\section{UPDATE AleRTS}

\section{Update Alert: Hydroxychloroquine or Chloroquine for the Treatment or Prophylaxis of COVID-19}

This report updates our living systematic review assessing hydroxychloroquine or chloroquine versus control therapy for the treatment of coronavirus disease 2019 (COVID-19) in hospitalized patients, which covered evidence available through 8 May 2020 (1). Using the same methods, we searched for and evaluated evidence published through 1 July 2020.

\section{Additional Eligible Evidence Identified}

Published reports of 3 studies previously available as preprints became available (2-4), enabling more thorough assessment for risk of bias. The risk of bias is now determined to be serious for $\mathrm{Yu}$ and colleagues' study (4), remains high for Tang and colleagues' study (2), and changed from moderate to serious for Mahévas and colleagues' study (3). We found 1 new randomized controlled trial (RCT) with high risk of bias (5), 1 new cohort study with moderate risk of bias (6), and 4 cohort studies that each had serious risk of bias (7-10). An additional large cohort study was published and subsequently retracted due to concerns about the veracity of the data $(11,12)$ and was not considered further. Press releases reported 3 large RCTs (RECOVERY, SOLIDARITY-WHO, and ORCHID-NIH) that ceased enrollment for the hydroxychloroquine versus control comparison early because of lack of efficacy in preliminary analyses (13-15). These trials had strong study designs, but other than press releases, no reports were available to assess.

The only new data on chloroquine came from Chen and colleagues' aforementioned RCT, which contained a chloroquine group that was compared with a control group (5). This RCT had high risk of bias and observed no deaths or severe disease progression, and all patients in both groups cleared the virus from the upper respiratory tract by day 10 (5). However, clinical recovery took fewer days in the chloroquine group than the control group.

\section{Updated Evidence Synthesis}

Supplement Tables 1 and 2 (available at Annals.org) provide updated unadjusted outcomes data (1-28). Given the risk of bias for individual studies and the conflicting direction and magnitude of results, the evidence from both RCTs and cohort studies remains insufficiently strong to support a benefit of hydroxychloroquine or chloroquine for treatment of COVID-19 in hospitalized patients. We were unable to identify a pattern by which risk of bias, dosage, duration of therapy, or other factors explained the conflicting findings. The strength of evidence remains insufficient for all safety outcomes.

\section{Discussion}

This update identified 1 new RCT, several new cohort studies, and more complete published reports of studies previously available as preprints; the conclusions are un- changed from the initial review. The newly available evidence has high risk of bias. There is insufficient evidence to support the effectiveness or safety of hydroxychloroquine or chloroquine for the treatment of COVID-19 in hospitalized patients.

The results of the RECOVERY, SOLIDARITY-WHO, and ORCHID-NIH trials could help to more definitively determine the role of this therapy for COVID-19.

\section{Adrian V. Hernandez, MD, PhD}

University of Connecticut Health Outcomes, Policy, and Evidence Synthesis Group and Hartford Hospital Department of Research Administration, Hartford, Connecticut

School of Pharmacy, Storrs, Connecticut

and Vicerrectorado de Investigación, Universidad San Ignacio de Loyola, Lima, Peru

\section{Yuani M. Roman, MD, MPH}

University of Connecticut Health Outcomes, Policy, and Evidence Synthesis Group and Hartford Hospital Department of Research Administration, Hartford, Connecticut

Vinay Pasupuleti, MD, MS, PhD

MedErgy HealthGroup, Yardley, Pennsylvania

Joshuan J. Barboza, MSc

Vicerrectorado de Investigación, Universidad San Ignacio de Loyola, Lima, Peru

\section{Michael White, PharmD}

University of Connecticut Health Outcomes, Policy, and Evidence Synthesis Group and Hartford Hospital Department of Research Administration, Hartford, Connecticut, and School of Pharmacy, Storrs, Connecticut

Disclaimer: The findings and conclusions in this document are those of the authors, who are responsible for its contents. The findings and conclusions do not necessarily represent the views of the Agency for Healthcare Research and Quality (AHRQ). No statement in this report should be construed as an official position of AHRQ or the U.S. Department of Health and Human Services.

Financial Support: By AHRQ (contract HHSA290-2015-00012I).

Disclosures: Disclosures can be viewed at www.acponline.org /authors/icmje/ConflictOfInterestForms.do?msNum=L20-0945.

Corresponding Author: C. Michael White, University of Connecticut School of Pharmacy, 69 North Eagleville Road, U-3092, Storrs, CT 06269; e-mail, charles.white@uconn.edu.

doi:10.7326/L20-0945

\footnotetext{
References

1. Hernandez AV, Roman YM, Pasupuleti V, et al. Hydroxychloroquine or chloroquine for treatment or prophylaxis of COVID-19: a living systematic review. Ann Intern Med. 2020. [PMID: 32459529] doi:10.7326/M20-2496

2. Tang $W$, Cao $Z$, Han M, et al. Hydroxychloroquine in patients with mainly mild to moderate coronavirus disease 2019: open label, randomised controlled trial. BMJ. 2020;369:m1849. [PMID: 32409561] doi:10.1136/bm] .m1849
}

This article was published at Annals.org on 15 July 2020. 
3. Mahévas M, Tran VT, Roumier M, et al. Clinical efficacy of hydroxychloroquine in patients with covid-19 pneumonia who require oxygen: observational comparative study using routine care data. BMJ. 2020;369:m1844. [PMID: 32409486] doi:10.1136/bmj.m1844

4. Yu B, Li C, Chen P, et al. Low dose of hydroxychloroquine reduces fatality of critically ill patients with COVID-19. Sci China Life Sci. 2020. [PMID: 32418114] doi:10.1007/s11427-020-1732-2

5. Chen L, Zhang ZY, Fu JG, et al. Efficacy and safety of chloroquine or hydroxychloroquine in moderate type of COVID-19: a prospective open-label randomized controlled study. medRxiv. Preprint posted online 22 June 2020. doi:10.1101/2020.06.19.20136093

6. Sbidian E, Josse J, Lemaitre G, et al. Hydroxychloroquine with or without azithromycin and in-hospital mortality or discharge in patients hospitalized for COVID-19 infection: a cohort study of 4,642 inpatients in France. medRxiv. Preprint posted online 16 June 2020. doi:10.1101/2020.06.16.20132597

7. Rosenberg ES, Dufort EM, Udo T, et al. Association of treatment with hydroxychloroquine or azithromycin with in-hospital mortality in patients with COVID-19 in New York State. JAMA. 2020. [PMID: 32392282] doi:10.1001 /jama.2020.8630

8. Ip A, Berry DA, Hansen E, et al. Hydroxychloroquine and tocilizumab therapy for COVID-19 patients - an observational study. medRxiv. Preprint posted online 21 May 2020. doi:10.1101/2020.05.21.20109207

9. Singh S, Khan A, Chowdhry M, et al. Outcomes of hydroxychloroquine treatment among hospitalized COVID-19 patients in the United States-real-world evidence from a federated electronic medical record network. medRxiv. Preprint posted online 12 May 2020. doi:10.1101/2020.05.12.20099028

10. Arshad S, Kilgore P, Chaudhry ZS, et al; Henry Ford COVID-19 Task Force. Treatment with hydroxychloroquine, azithromycin, and combination in patients hospitalized with COVID-19. Int J Infect Dis. 2020. [PMID: 32623082] doi:10.1016/j.ijid.2020.06.099

11. Mehra MR, Ruschitzka F, Patel AN. Retraction-Hydroxychloroquine or chloroquine with or without a macrolide for treatment of COVID-19: a multinational registry analysis. Lancet. 2020;395:1820. [PMID: 32511943] doi:10.1016 /S0140-6736(20)31324-6

12. Rosenthal M. 2 papers about drug therapy for COVID-19 retracted from prestigious journals. Accessed at www.pharmacypracticenews.com/Covid-19 /Article/05-20/2-Papers-AboutDrug-Therapy-in-COVID-19-Retracted-From -Prestigious-Journals/58677 on 6 July 2020.

13. RECOVERY trial. No clinical benefit from use of hydroxychloroquinein hospitalised patients with COVID-19. 5 June 2020. Accessed at www.recoverytrial .net/news/statement-from-the-chief-investigators-of-the-randomised -evaluation-of-covid-19-therapy-recovery-trial-on-hydroxychloroquine-5-june -2020-no-clinical-benefit-from-use-of-hydroxychloroquine-in-hospitalised -patients-with-covid-19 on 6 July 2020.

14. World Health Organization. WHO discontinues hydroxychloroquine and lopinavir/ritonavir treatment arms for COVID-19. 4 July 2020. Accessed at www.who .int/news-room/detail/04-07-2020-who-discontinues-hydroxychloroquine -and-lopinavir-ritonavir-treatment-arms-for-covid-19 on 6 July 2020.

15. National Institutes of Health. NIH halts clinical trial of hydroxychloroquine: study shows treatment does no harm, but provides no benefit. 20 June 2020 . Accessed at www.nih.gov/news-events/news-releases/nih-halts-clinical-trial -hydroxychloroquine on 6 July 2020.
16. Boulware DR, Pullen MF, Bangdiwala AS, et al. A randomized trial of hy droxychloroquine as postexposure prophylaxis for covid-19. N Engl J Med 2020. [PMID: 32492293] doi:10.1056/NEJMoa2016638

17. Chen J, Ping L, Li L, et al. Preliminary study of hydroxychloroquine sulfate in treating common coronavirus disease (COVID-19) patients in 2019. Journal of Zhejiang University (Medical Science). 2020. doi:10 .3785/j.issn.1008-9292.2020.03.03

18. Barbosa J, Kaitis D, Freedman R, et al. Clinical outcomes of hydroxychloroquine in hospitalized patients with COVID-19: a quasi-randomized comparative study. Accessed at www.dropbox.com/s/urzapkyij542qx5/NEJM_Clinical $\% 20$ Outcomes\%20 of\%20Hydroxychlorquine\%20in\%20Patients\%20 with \%20COVID19.pdf.pdf.pdf.pdf.pdf.pdf.pdf.pdf?dl=0 on 10 July 2020.

19. Magagnoli J, Narendran S, Pereira F, et al. Outcomes of hydroxychloroquine usage in United States veterans hospitalized with Covid-19. medRxiv. Preprint posted online 23 April 2020. doi:10.1101/2020.04.16.20065920 20. Mallat J, Hamed F, Balkis M, et al. Hydroxychloroquine is associated with slower viral clearance in clinical COVID-19 patients with mild to moderate disease: a retrospective study. medRxiv. Preprint posted online 2 May 2020. doi: 10.1101/2020.04.27.20082180

21. Membrillo de Novales FJ, Ramírez-Olivencia G, Estébanez M, et al. Early hydroxychloroquine is associated with an increase of survival in COVID-19 patients: an observational study. Preprints. Preprint posted online 6 May 2020. doi:10.20944/preprints202005.0057.v1

22. Geleris J, Sun Y, Platt J, et al. Observational study of hydroxychloroquine in hospitalized patients with covid-19. N Engl J Med. 2020;382:2411-8. [PMID: 32379955] doi:10.1056/NEJMoa2012410

23. Mahévas $M$, Tran VT, Roumier M, et al. No evidence of clinical efficacy of hydroxychloroquine in patients hospitalized for COVID-19 infection with oxygen requirement: results of a study using routinely collected data to emulate a target trial. medRxiv. Preprint posted online 14 April 2020. doi:10.1101/2020 04.10.20060699

24. Chen Z, Hu J, Zhang Z, et al. Efficacy of hydroxychloroquine in patients with COVID-19: results of a randomized clinical trial. medRxiv. Preprint posted online 10 April 2020. doi:10.1101/2020.03.22.20040758

25. Gautret $P$, Lagier JC, Parola P, et al. Hydroxychloroquine and azithromycin as a treatment of COVID-19: results of an open-label non-randomized clinical trial. Int J Antimicrob Agents. 2020:105949. [PMID: 32205204] doi:10.1016/j .ijantimicag.2020.105949

26. Borba MG, Val FdA, Sampaio VS, et al. Chloroquine diphosphate in two different dosages as adjunctive therapy for hospitalized patients with severe respiratory syndrome in the context of coronavirus (SARS-CoV-2) infection: preliminary safety results of a randomized, double-blinded, phase IIb clinical trial (CloroCovid-19 Study). medRxiv. Preprint posted online 16 April 2020. doi:10.1101/2020.04.07.20056424

27. Borba MGS, Val FFA, Sampaio VS, et al; CloroCovid-19 Team. Effect of high vs low doses of chloroquine diphosphate as adjunctive therapy for patients hospitalized with severe acute respiratory syndrome coronavirus 2 (SARS-CoV-2) infection: a randomized clinical trial. JAMA Netw Open. 2020;3: e208857. [PMID: 32339248] doi:10.1001/jamanetworkopen.2020.8857

28. Huang M, Li M, Xiao F, et al. Preliminary evidence from a multicenter prospective observational study of the safety and efficacy of chloroquine for the treatment of COVID-19. medRxiv. Preprint posted online 4 May 2020. doi:10 $.1101 / 2020.04 .26 .20081059$ 